\title{
Relationship between Spiritual Practices and Psychological Well- Being among Hindus
}

\author{
Ruchi Singh ${ }^{1}$ *
}

\section{ABSTRACT}

Spiritual people perform some spiritual practices for attaining psychological well-being, mental peace, and different types of healings and for many other purposes. The main aim of the present study is to investigate the relationship between spiritual practices and psychological well-being among Hindus. Spiritual practices positively affect psychological well-being. In the present study, Spiritual Practices Scale-Hindus (SPS-H) developed by Singh and Husain (2014) and Psychological Well-being Scale developed by Prakash and Bhogle (1995) were administered on 130 Hindus (89 male and 41 female). They were drawn from different temples situated in Aligarh and Agra districts of U.P. Data was analysed by using Pearson product moment correlation to examine the relationship between the scores obtained on the spiritual practices and psychological well-being scales. The Significant positive relationship was found between spiritual practices and psychological well-being among Hindus.

Keywords: Spiritual Practices, Psychological Well-Being, Hindus.

Spirituality is a salient feature in the conceptualization of well being among the people of Asia. Now and these days due to better living conditions and increased life expectancy the problems of human life are rising day by day. The increasing process of urbanization, industrialization and modernization is ushering changes in the overall human well-being. The main objective of present study is to make human life happy and pleasant though performing spiritual practices.

\section{Spiritual Practices}

In India the terms- spiritual practices and religious practices are used interchangeably. Spiritual practices are also known as religious practices, rituals or spiritual/religious exercises. Spiritual practices are the actions or activities related to the spirituality/religiosity like prayer, yoga, meditation, recitation of religious literature or scriptures, visiting holy shrines, singing or listening psalms, hymns and chanting or enchanting mantras etc. spiritual practices are usually practiced by the spiritual/religious people for achieving many purposes like cultivating spirituality, enhancing holistic well-being, gaining peace of mind, finding meaning and purpose in life and also for giving positive direction to the human life.

\footnotetext{
${ }^{1}$ Research Scholar, Department of Psychology, Aligarh Muslim University, Aligarh *Corresponding Author

(C) 2015 I R Singh; licensee IJIP. This is an Open Access Research distributed under the terms of the Creative Commons Attribution License (http://creativecommons.org/licenses/by/2.0), which permits unrestricted use, distribution, and reproduction in any Medium, provided the original work is properly cited.
} 


\section{Psychological well-being}

According to Sinha (1990) it is difficult to define psychological well-being. It has been taken to consist of desirability or discomfort and from any disturbance of mental functioning. It is somewhat a malleable concept which has to do with person's feelings about his/her daily life activities and experiences, and these feelings may range from extreme negative mental states or psychological strains (such as depression, worry, anxiety, frustration, unhappiness, dissatisfaction and emotional exhaustion) to more positive states (such as positive mental health of joy, satisfaction, happiness and the like) which has been identified as positive mental health, which are not only the simple state of "absence of" worry or unhappiness, but also are the states which relate one to sound mental health and include favourable self-esteem and success (Jahoda, 1958; Warr, 1978).

\section{Spiritual practices and Psychological well -being}

Although ample numbers of studies have been conducted on spiritual practices in relation to well- being, here we cite some studies on the relationship between spiritual practices and psychological well-being.

Maltby, Lewis and day (1999) conducted a correlational study on a sample of 474 UK students (251 males, 223 females) to examine the role of religious acts within the relationship between measures of religious orientation and psychological well-being. Found a number of significant correlations between measures of religiosity and psychological well-being, a multiple regression analysis using identifiable religious components suggests that frequency of personal prayer is the dominant factor in the relationship between religiosity and psychological well-being.

A study conducted at Duke University revealed that religious activities, attitudes, and spiritual beliefs were more strongly prevalent in older hospitalized patients and were positively associated with better psychological and physical health, greater perception of social support than younger hospitalized patients. Furthermore, patients who categorized themselves as neither spiritual nor religious tended to have greater medical co morbidities (Koenig, George and Titus, 2004).

Rissell, Miller, Lioyd and Williams (2014) conducted a study to examine the effects of Bikram Yoga on two aspects of psychological well-being: core self-evaluation (CSE) and life satisfaction. Findings of the study suggested that life satisfaction and CSE each improved over the course of the intervention. It is likely that the well-known effects of participating in intense physical exercise also contributed to improvements in psychological well-being.

Greenfield, Vaillant and Marks (2007) Examined whether formal religious participation and daily spiritual experiences are independently and equally associated with diverse dimensions of psychological well-being (negative affect, positive affect, purpose in life, positive relations with others, personal growth, self-acceptance, environmental mastery, and autonomy). Data came 
from 1,801 respondents in the 2005 National Survey of Midlife in the U.S. (MIDUS). Results of the study suggest that daily spiritual experiences and formal religious participation are linked in separate and non-equal ways with psychological well-being.

Maselko and Kubzansky (2006) investigated the independent linkages of religious participation and spiritual experiences with several aspects of psychological well-being using the data from respondents in the 1998 General Social Survey (with a mean age of 44.67 years). Results indicated that who report weekly religious participation and having a daily spiritual experience were both independently associated with higher levels of global happiness. Also among both males and females, weekly religious participation-but not daily spiritual experience-was associated with lower levels of psychological distress; and among males only, weekly religious participation was associated with higher levels of life satisfaction.

Mirola (1999) found that higher level of religious involvement was associated with fewer depressive symptoms among females, but not among males; and Norton and colleagues (2006) found that the higher level of religious involvement was associated with decreased likelihood of depression among females, but increased likelihood of depression among males.

Now, on the basis of the above cited research studies it should be clear that spiritual practices directly or indirectly affect the psychological well-being of the people who perform spiritual/religious practices regularly in the positive manner. So, on the basis of these studies it can be predicted that those people who tend to engage in the spiritual/religious practices are more likely to be psychologically well. To test this hypothesis the present study has been conducted to test whether the spiritual practices and psychological well-being are positively related among Hindus also or not.

\section{OBJECTIVE}

The objectives of the present study were as follows:

1. To examine the relationship between spiritual practices and psychological wellbeing among over all sample and gender-wise.

2. To examine the relationship between the dimensions of spiritual practices in relation to psychological well-being among over all sample and gender-wise.

\section{HYPOTHESIS}

On the basis of the aforementioned objectives following alternative hypothesises were formulated:

1. There will be significant relationships between spiritual practices and psychological well-being among over all sample and gender-wise.

2. There will be significant relationships between the dimensions of spiritual practices and psychological well-being among over all sample and gender-wise. 


\section{METHODOLOGY}

PARTICIPANTS

Participants for the present study were 204 Hindu religious devotees (127 Males and 77 Females). They were randomly selected from different temples situated in Aligarh and Agra districts of U.P. Mean and SD of the age of total and gender-wise participants were 34.40 and 13.66, male $=37.09$ and 14.27 and, female $=30.00$ and 11.35 respectively.

\section{MEASURES}

In the present study two scales were used in order to collect the data from Hindu religious devotees about their spiritual practices they perform and psychological well-being they have.

\section{Spiritual Practices Scale-Hindus:}

Spiritual Practices Scale-Hindus (SPS-H) developed by Singh and Husain (2015) was used in this study. The SPS-H assesses spiritual practices performed by Hindu religious devotees. The SPS-H consisted of 15 items (11 items along a 5-point Likert scale and 4 items along a 3-point Likert scale). It is a three dimensional scale namely:

Positive Transformation: This dimension consisting of 6 items (1, 2, 8, 9, 11, and 14).

Self-purification: This dimension consisting of 4 items $(7,10,12$, and 13).

Expanding Awareness: This dimension consisting of 5 items (3, 4, 5, 6, and 15).

The Chronbach's alpha reliability was $=0.85(n=597)$. Validity of the scale was determined by calculating the percent of variance (factorial/ construct validity) construct validity was 53.43.

All items of the SPS were scored in the positive direction i.e. from 5 to 1 and 3 to 1 according to the items. Minimum and Maximum scores ranges from 15 to 67 in the scale. The higher the scores, the more the subjects tend to engage in spiritual practices along the dimensions described. In the present study, Hindi version of the SPS-H was used.

\section{Psychological Well-Being Scale:}

Psychological well-being Questionnaire developed by Bhogle and Prakash (1995) was used to measure Psychological well-being. The questionnaire contains 28 items with a forced choice (Yes/No) format. The maximum possible score is twenty eight and minimum is zero. High score indicates higher level of psychological well-being. In the tool, 10 statements (4, 5, 6, 10, 12, 14, 15, 16, 21 and 24) are negatively keyed (score 0 for Yes and 1 for No) and the remaining 18 statements are positive (score 1 for Yes and 0 for No). Scores are classified as (0-9) as low psychological well-being, (10-20) as intermediate psychological well-being and (21-28) as high psychological well-being. 
The PWB questionnaire consisted of 13 factors including meaninglessness, somatic symptoms, selflessness, positive affects, daily activity, life satisfaction, suicidal ideas, personal control, social support, tension, wellness, general efficiency and satisfaction. The test - retest reliability coefficient is 0.72 and internal consistency coefficient is 0.84 . In terms of validity it correlate well, both with subjective well-being scale $(\mathrm{r}=0.622)$ and with general well-being measure $(\mathrm{r}=$ 0.484). The authors have reported satisfactory validity of the questionnaire.

\section{PROCEDURE}

The data were collected individually from the subjects. Prior to data collection, the investigator established rapport with the subjects and explained the purpose of the investigation. Subjects generally took 10-15 minutes in completing the scales.

\section{DATA ANALYSIS}

Pearson product moment correlation was used to examine the relationship between the obtained scores on Spiritual Practices Scale-Hindus (SPS-H) and on Psychological Well-being Questionnaire (PWB) among over all Hindus and gender wise.

\section{RESULTS AND DISCUSSION}

Table 1: Coefficients of correlation between Spiritual Practices and Psychological Well-being among total number of Hindu participants as well as gender wise.

\begin{tabular}{|c|c|}
\hline Participants & SPS/PWB \\
\hline Males $\quad(127)$ & $0.37 * *$ \\
\hline Females (77) & 0.22 \\
\hline Total (204) & $0.31 * *$ \\
\hline
\end{tabular}

As it can be seen from Table 1 that the significant positive correlation coefficients were found between spiritual practices and psychological well-being $(\mathrm{r}=0.31, \mathrm{p}<.01)$ in total participants. If we look at this relationship gender-wise, it shows that spiritual practices have significant positive association with psychological well-being in males $(\mathrm{r}=0.37, \mathrm{p}<.01)$. On the basis of these findings it can be inferred that the more the people tend to engage in the spiritual practices the more the possibility that they are psychologically well. So it can be concluded that spiritual/religious practices directly or indirectly affect the psychological well-being of the people.

Spiritual Practices Scale- Hindus (SPS-H) has three dimensions including Positive Transformation, Self-purification and Expanding Awareness. The following table consists of index of correlations between the dimensions of spiritual practices in relation to psychological well-being for total as well as gender wise. 
Table 2: Coefficients of correlation between dimensions of Spiritual Practices (Positive Transformation, Self-purification and Expanding Awareness) with Psychological Well-being among total number of Hindu participants, and gender wise.

\begin{tabular}{ll}
\hline Participants & \multicolumn{1}{|c}{$\mathbf{P T} / \mathbf{P W B}$} \\
& $\mathbf{r}$ \\
\hline Males (127) & $0.38^{* *}$ \\
Females (77) & 0.19 \\
Total (204) & $0.31^{* *}$ \\
& SP/PWB \\
Males (127) & $0.30^{* *}$ \\
Females (77) & $0.26^{*}$ \\
Total (204) & $0.29^{* *}$ \\
& $\mathbf{E A} / \mathbf{P W B}$ \\
Males (127) & $0.30^{* *}$ \\
Females (77) & 0.16 \\
Total (204) & $0.24^{* *}$ \\
\end{tabular}

Note: For, $P . T=$ Positive Transformation, S.P= Self-Purification, E.A=Expanding Awareness, ${ }^{*} p<.05, * * p<.01$.

(a) Positive Transformation and Psychological Well-Being: It may be noted from the above table that the coefficient of correlation between positive transformation dimension of spiritual practices with psychological well-being was found significant positive at the .01 level of significance in Hindu males. The relationship between these variables was also found significant at the .01 level of significance in total sample.

(b) Self-Purification and Psychological Well-Being: It can be seen from the above table that the coefficients of correlation between self-purification dimension of spiritual practices with psychological well-being were found to be significant at the .01 and .05 levels of significance in males, females, and total participants Hindu religious devotees.

(c) Expanding Awareness and Psychological Well-Being: The coefficients of correlation between expanding awareness dimension of spiritual practices with psychological well-being were found to be significant at the .01 level of significance in males and total number of Hindu religious devotees (cf. Table 2).

The findings of the present study showed that the relationship between spiritual/religious practices and psychological well-being were found to be significantly positive among Hindus. On the basis of the findings it can be concluded that people who are involved in observing spiritual/religious practices their psychological well-being is high. The findings of the present 
study can also be supported by some of the earlier studies (Greenfield, Vaillant, \& Marks, 2007; Koenig, George, \& Titus, 2004; Maltby, Lewis, \& Day, 1999; Maselko Kubzansky, 2006; Rissell, Miller, Lioyd, \& Williams, 2014).

\section{REFERENCES}

Bhogle, S., \& Prakash, I. J. (1995). Development of the psychological wellbeing (PWB) questionnaire. Journal of personality and clinical studies, 11(1\&2), 5-9.

Greenfield, E.A., Vaillant, G. \& Marks, N.F. (2007). Formal religious participation and daily spiritual experiences: Separate but equal, linkages with psychological well-being? Center for Demography and Ecology Working Paper No. 2007-01, University of WinconsinMadison.

Jahoda, M. (1958). Current concepts of positive mental health. New York: Basic Books.

Koenig, H. G., George, L. K., \& Titus, P. (2004). Religion, spirituality, and health in medically ill hospitalized older patients. Journal of the American Geriatrics Society, 52(4), 554562.

Maltby, J., Lewis, C. A., \& Day, L. (1999). Religious orientation and psychological well-being: The role of the frequency of personal prayer. British Journal of Health Psychology, 4, 363-378.

Maselko, J., \& Kubzansky, L. D. (2006). Gender differences in religious practices, spiritual experiences and health: results from the general social survey. Social Science and Medicine 62(11), 2848-2860.

Mirola, W. A. (1999). A refuge for some: gender differences in the relationship between religious involvement and depression. Sociology of Religion 60, 419-437.

Norton, M. C., Skoog, I., Franklin, L. M., Corcoran, C., Tschanz, J. T., Zandi, P. P., Breitner, J. C., Welsh-Bohmer, K. A., \& Steffens, D. C. (2006). Gender differences in the association between religious involvement and Depression: the cache county (utah) study. Journal of Gerontology: Psychological Sciences 61(3), 129-136.

Rissel, A. A., Miller, B. K., Lioyd. L. K., \& Williams, J. S. (2014). Hot, sweaty, and satisfied: Effects of Bikram yoga on psychological well-being. Journal of Behavioral Health, 3(1), 71-76.

Sinha, D. (1990). Concept of psychosocial well-being: Western and Indian perspectives. NIMHANS Journal, 8, 1-11.

Singh, R., \& Husain, A. (2015). Manual of spiritual practices scale for Hindus (SPS-H). New Delhi: Prasad Psycho Corporation.

Warr, P.B. (1978). A study of psychological well-being. British Journal of Psychology, 69, 111121. 